Netzwerkentwicklung in der Jugendberufshilfe 
Susanne Weber (Hrsg.)

\section{Netzwerkentwicklung in der Jugendberufshilfe}

Erfahrungen mit Institutioneller Vernetzung im ländlichen Raum

Leske + Budrich, Opladen 2001 
Gedruckt auf säurefreiem und altersbeständigem Papier.

Die Deutsche Bibliothek - CIP-Einheitsaufnahme

Ein Titeldatensatz für diese Publikation ist bei Der Deutschen Bibliothek erhältlich.

ISBN 978-3-8100-3156-3

ISBN 978-3-322-99365-6 (eBook)

DOI 10.1007/978-3-322-99365-6

() 2001 Leske + Budrich, Opladen

Das Werk einschließlich aller seiner Teile ist urheberrechtlich geschützt. Jede Verwertung außerhalb der engen Grenzen des Urheberrechtsgesetzes ist ohne Zustimmung des Verlages unzulässig und strafbar. Das gilt insbesondere für Vervielfältigungen, Übersetzungen, Mikroverfilmungen und die Einspeicherung und Verarbeitung in elektronischen Systemen. 
Die Drucklegung dieses Bandes wurde ermöglicht durch die großzügige Unterstützung von:

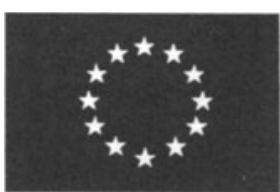

Europäische Union
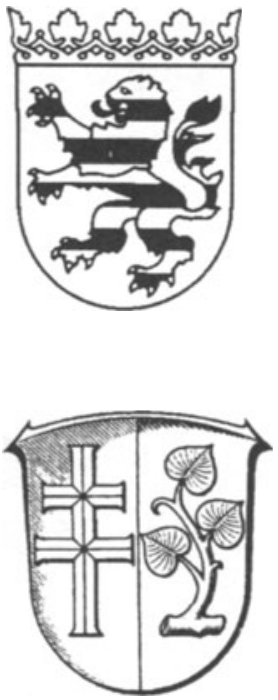

Kreisausschuss des Landkreises

Hersfeld-Rotenburg

Trägerverbund Lebens- und Berufshilfe Vogelsberg

- Gemeinnützige Schottener Reha-Einrichtungen $\mathrm{GmbH}$

- Hilfe für das verlassene KIND e.V.

- NEUE ARBEIT Vogelsberg gGmbH 


\section{Inhalt}

\section{Einleitung}

Benno Hafeneger

Vernetzung - ein produktiver Suchbegriff in der Neuorientierung der

Jugendhilfe

Susanne Weber

Institutionelle Vernetzung zwischen Wohlfahrtspluralismus und

Netzwerkökonomie

\section{Tendenzen, Trends, Programme}

Ralph Rußmann, Ariane Schwedler

Neue Rahmenbedingungen, neue Anforderungen und neue

Handlungsmuster pädagogischer Professionalität

Hanjo Schild

Vom Verbund zur Vernetzung:

Zur Geschichte und den aktuellen Herausforderungen institutioneller

Vernetzung in der Jugendberufshilfe

Nicole Benthin, Rita Hockerts

Regionale Netzwerke im ländlichen Raum -

Das Projekt Youthstart Network

\section{Schlaglichter und Perspektiven der Akteure vor Ort}

\section{Heiner Brülle}

Wege zur Berufsbildung für Alle - Kommunale Strategien einer aktiven Berufsbildungspolitik für Benachteiligte

Annette Allendorf, Christiane Becker-Ott

Perspektiven für junge Frauen im ländlichen Raum:

Vernetzen im Arbeitskreis Mädchenarbeit

Bodo Kester

Innovation in der Zusammenarbeit pädagogischer Einrichtungen:

Der Trägerverbund

Harald Finke

Regionalentwicklung in Public Private Partnership für berufliche Perspektiven Jugendlicher 


\section{Projekterfahrung und Reflexion}

Martina Baumert, Christiane Brechlin

Die Entwicklung regionaler Netzwerke im Landkreis

Hersfeld-Rotenburg

Gert Straßer

Lernprozesse auf dem Weg zu einer regionalen Vernetzung -

Anmerkungen zur wissenschaftlichen Begleitung im

Landkreis Hersfeld-Rotenburg

Angelika Stietz

Erfahrungen mit der Initiierung von lokalen Netzwerken der

Jugendberufshilfe im Odenwaldkreis: Lernen aus Chancen und Risiken

Elke Schimpf

Vernetzung als Ziel: Zur begrifflichen Definition ihrer

Operationalisierung und Erfolgsmessung

Ina Stockmann

Regionale Vernetzung mit Vision

Susanne Weber

Schnecke und Tausendfüßler.

Zur Bedeutung von Metaphern und Visionen für regionale Vernetzung

\section{Vernetzung mit Verfahren}

Susanne Weber

Wie vernetzen? Systematisches Vorgehen mit Vernetzungsverfahren, Projektplanung und Evaluation

Nicole Benthin, Martina Baumert

Selbstevaluation als Methode der Qualitätsentwicklung,

Prozesssteuerung und summativen Evaluation

Sabine Lauber

Elektronische Vernetzung nutzen - virtuell und real

\section{Ausblick}

Nicole Benthin, Susanne Weber

Lernprozesse, Erfahrungen und Empfehlungen zur Entwicklung von

Netzwerken im ländlichen Raum 